\title{
A Quality Improvement Initiative to Reduce Postoperative Delirium among Cardiac Surgery Patients
}

\author{
Rohan M. Sanjanwala ${ }^{1}$, Brett Hiebert ${ }^{1}$, David Kent ${ }^{1}{ }^{\mathbb{D}}$, Sandy Warren ${ }^{1}$, Hilary Grocott ${ }^{1,2,3}$ \\ and Rakesh C. Arora 1,2,3,* \\ 1 Cardiac Science Program, St Boniface Hospital, Winnipeg, MB R2H 2A6, Canada; \\ rsanjanwala@sbgh.mb.ca (R.M.S.); bhiebert3@sbgh.mb.ca (B.H.); dkent@sbgh.mb.ca (D.K.); \\ swarren@sbgh.mb.ca (S.W.); hgrocott@sbgh.mb.ca (H.G.) \\ 2 Department of Anesthesia, Perioperative and Pain Medicine, Max Rady College of Medicine, \\ University of Manitoba, Winnipeg, MB R3E 0W2, Canada \\ 3 Department of Surgery, Section of Cardiac Surgery, Max Rady College of Medicine, University of Manitoba, \\ Winnipeg, MB R3E 0W2, Canada \\ * Correspondence: rarora@sbgh.mb.ca; Tel.: +1-204-258-1078; Fax: +1-204-231-4624
}

Citation: Sanjanwala, R.M.; Hiebert, B.; Kent, D.; Warren, S.; Grocott, H.; Arora, R.C. A Quality Improvement Initiative to Reduce Postoperative Delirium among Cardiac Surgery Patients. Geriatrics 2021, 6, 111. https://doi.org/10.3390/geriatrics 6040111

Academic Editor: Phyo Kyaw Myint

Received: 13 October 2021

Accepted: 12 November 2021

Published: 16 November 2021

Publisher's Note: MDPI stays neutral with regard to jurisdictional claims in published maps and institutional affiliations.

Copyright: (c) 2021 by the authors. Licensee MDPI, Basel, Switzerland. This article is an open access article distributed under the terms and conditions of the Creative Commons Attribution (CC BY) license (https:/ / creativecommons.org/licenses/by/ $4.0 /)$.

\begin{abstract}
Patients following cardiac surgery commonly experience post-operative delirium (POD) during their postoperative hospital stay. A multifaceted, specialty wide, quality improvement (QI) project was undertaken for patients experiencing POD. The goal was to develop a reduction in POD care bundle (rPOD-a structured patient care program) that encompasses efficient preoperative risk factor identification and a postoperative patient-care process to ensure early POD identification and treatment. The following steps were taken to implement the rPOD care bundle including: (a) Developing a quality driven, evidence-based guideline for the perioperative cardiac surgery health care team, (b) identifying and addressing local barriers to implementation, (c) selecting performance measures to assess intervention adherence and patient outcomes, and (d) ensuring that all patients receive the interventions through staff engagement and education, and regular project evaluation. Trends of process measures and quality improvement measures were examined. An increasing trend in the rate of postoperative delirium screening during implementation of rPOD intervention was demonstrated. This quality improvement study provides a bases for future postoperative delirium reduction interventions.
\end{abstract}

Keywords: postoperative delirium; postoperative care; quality improvement; cardiac surgery; care strategies

\section{Introduction}

Delirium is an acute brain dysfunction characterized by a fluctuating disturbance of consciousness with inattention and cognition and perception deficits [1,2]. It is the most common neuropsychological complication following cardiac surgery, with the most recent estimates of prevalence ranging from $25 \%$ to $50 \%[3,4]$. While postoperative delirium (POD) may resolve in hospital, the patients experiencing delirium are at a higher risk of worse in-hospital and post-discharge outcomes. Numerous studies among cardiac surgery patients have demonstrated that POD increases the risk of postoperative mortality and of prolonged length of hospital stay [5-8]. In addition, such patients are at a higher risk of functional decline both physically and mentally, resulting in post-discharge poor quality of life, as well as a higher rate of nursing home placement [5-8]. There has been extensive research documenting the short- and long-term hazards associated with POD. In the same vein, many critical care societies have published care bundles to support institutional patient-care processes facilitating early identification and treatment of POD. One such example would be of the society of critical care medicine published ABCDEFICU liberation 2010 and PAD (Pain, agitation and delirium) guidelines in 2013. However, 
the condition remains frequently unrecognized (in three out of four ICU patients), and under-appreciated during hospitalization $[9,10]$.

Hospital-wide strategies focused on reducing POD are essential to improving clinical outcomes of surgery, as well as to improving patient-related outcomes including postoperative cognitive functioning. Through this knowledge translation-quality improvement initiative, the goal was to develop steps essential to implement an rPOD care bundle, centered around assessing baseline vulnerability (preoperative risk factor assessment), implementing preventative strategies, as well as early identification and management of delirium based on the available best practice evidence.

This project was implemented through a validated QI model (Figure 1) [11]. Here, we describe our collaborative healthcare improvement initiative carried through the following four steps: (1) summarizing evidence to identify potentially beneficial interventions, (2) identifying local barriers to implementation, (3) selection and development of performance measures and, (4) ensuring that all patients receive the interventions. The last step follows an iterative " $4 \mathrm{E}$ " algorithm to engage and educate front line staff, execute the intervention and evaluate performance using objective measurement tools (Figure 1) [11].

\section{Overall concepts}

Envision the problem within the larger healthcare system

Engage collaborative multidisciplinary teams centrally (stages 1-3) and locally (stage 4)

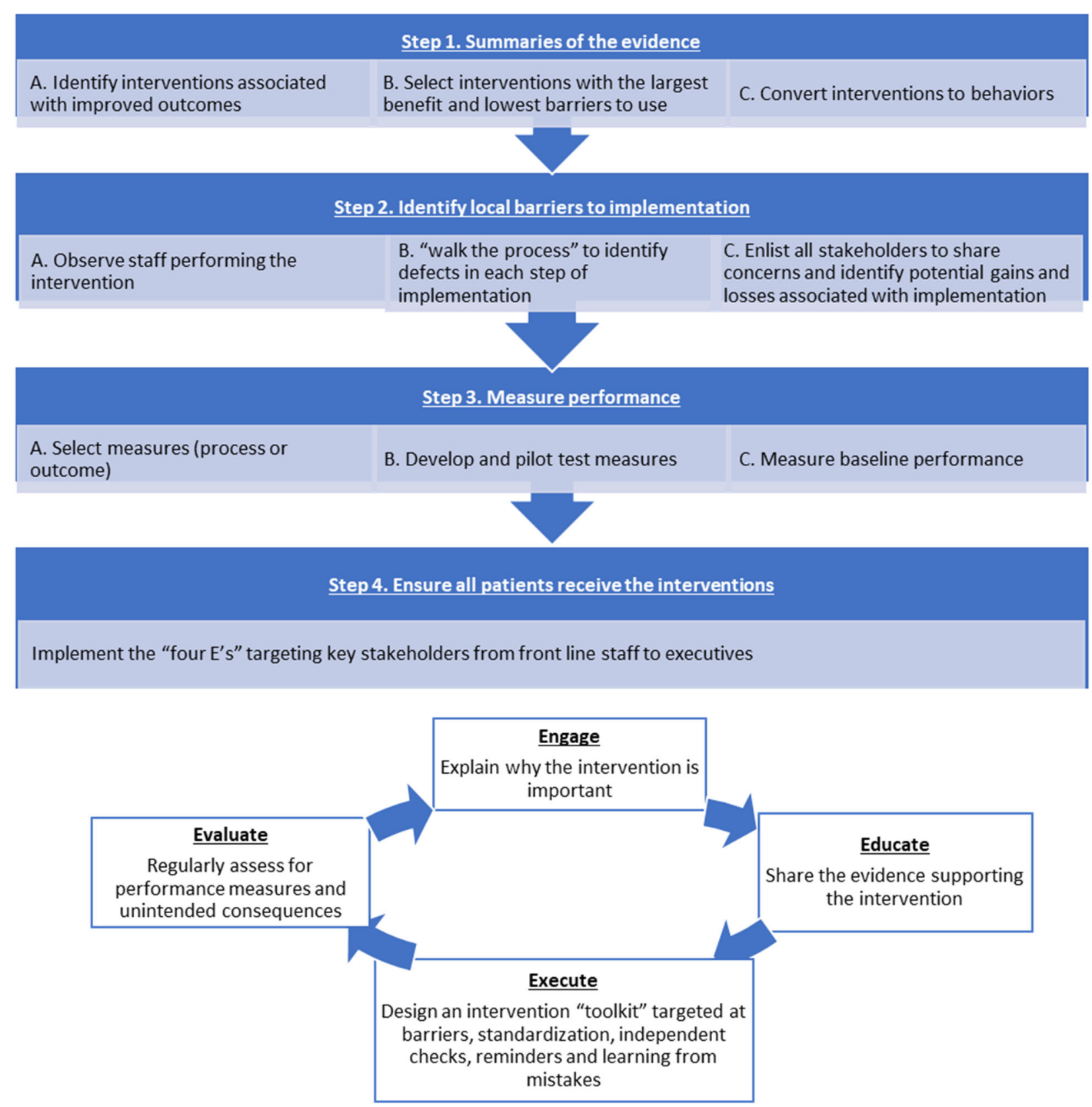

Figure 1. A model to implement quality improvement intervention in a healthcare setting. 
The purpose of this quality improvement project was to develop and implement a structured program to assess risk factors and to reduce incidence, early identification and prompt treatment of POD among the post-cardiac surgery ICU patients. This project targeted health care providers in the cardiac pre-assessment clinic (CPAC), cardiac surgery in-patient unit (CSIU), intensive care cardiac surgery (ICCS), cardiology inpatient unit, inclusive of nursing staff, physician assistants, physicians, as well as cardiac surgery patients and their caregivers.

The global aim of this quality improvement project was to decrease the prevalence of postoperative delirium among cardiac surgery patients at our center. The objective of this paper is to describe a multifaceted, quality improvement undertaking for the reduction of postoperative delirium, via prevention and management, in a cardiac surgery unit within a tertiary care hospital. In doing so, the study team discusses barriers encountered during the QI process and solutions to those barriers, along with the issues concerning staff adherence and long-term sustainability in order to provide relevant information for other cardiac surgery units that may wish to undertake a similar project.

\section{Methods}

\subsection{Context for the QI Project}

The rPOD quality improvement initiative was carried out at the St. Boniface Hospital (tertiary care center for the province of Manitoba, Cardiac Science Program including CPAC, ICCS, and CSIU). The multidisciplinary delirium working group, the perioperative health care providers, Winnipeg Regional Health Authority (WRHA), and cardiovascular surgery patients were the key stakeholders.

\subsection{Use of an Established QI Model}

The rPOD care bundle was implemented starting in 2012 with its completion in 2016. Here, we have employed an established QI model (Figure 1, Table 1) for improving the quality of care for cardiac surgery patients and to reduce the postoperative delirium prevalence among the cardiac surgery patients. The strategies were employed across the time frame, which was consecutive, but at times simultaneous.

Table 1. Quality improvement model.

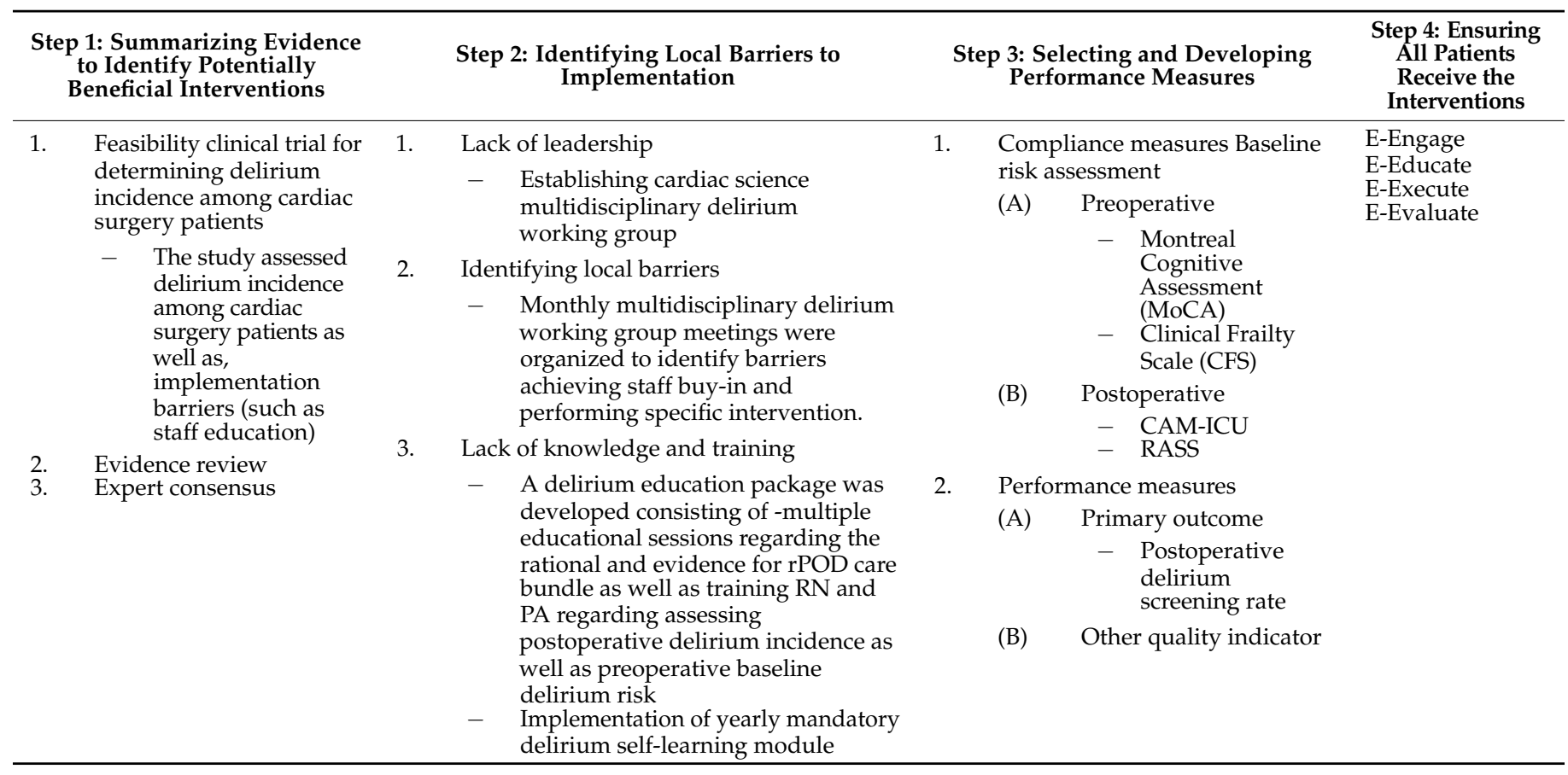

The table describes the adaption of a previously validated quality improvement model and provides a stepwise implementation of the rPOD care bundle. 


\subsection{Applying the QI Model to Reduce Postoperative Delirium among the Cardiac Surgery Patients Overall Considerations}

The improvement process involved a large patient care system involving an extensive multidisciplinary collaboration. A key first step was establishing a multidisciplinary team (i.e., delirium working group) to design and implement the project. This process was initiated by a cardiac surgeon (RA) with extensive QI experience and who is the director of ICCS, as well as the section head for the section of cardiac surgery. The other members of the delirium working group included an anesthetist (HG), a nurse champion (SW), as well as the perioperative cardiac surgery nursing staff.

Step 1: Summarize the Evidence

Our QI team developed guidelines targeted towards reducing postoperative delirium. The rPOD care bundle was developed based on our previous experience, the best evidence from the literature and through expert consensus. The rPOD care bundle consists of 3 domains as follows (Table 2):

Table 2. Components of rPOD care bundle.

\begin{tabular}{|c|c|c|}
\hline $\begin{array}{l}\text { Preoperative Intervention (CPAC, CSIU, } \\
\text { 5A)-Preoperative Assessment Package }\end{array}$ & Operative Intervention & Postoperative Intervention-ICCS \\
\hline $\begin{array}{ll}\text { 1. } & \text { Cognitive assessment-MoCA } \\
\text { 2. } & \text { Frailty Screening-CSF } \\
\text { 3. } & \text { "Getting to know you" form } \\
\text { 4. } & \text { Delirium brochure patient education } \\
\text { 5. } & \text { Family brochure-family mental health } \\
\text { 6. } & \text { Delirium score card } \\
\text { 7. } & \text { PCP letter for mental health }\end{array}$ & $\begin{array}{ll}\text { 8. } & \text { Timeout-Delirium score card } \\
\text { 9. } & \text { Cerebral capnography and EEG } \\
\text { directed anesthesia for high } \\
\text { risk cases }\end{array}$ & $\begin{array}{l}\text { 10. A four hourly delirium screening } \\
\text { using Confusion Assessment } \\
\text { Method in intensive care unit } \\
\text { (CAM ICU) } \\
\text { 11. CPOT pain assessment } \\
\text { 12. Non-pharmacological intervention } \\
\text { 13. Early mobility } \\
\text { 14. PCP-delirium information letter } \\
\text { 15. Delirium order set }\end{array}$ \\
\hline
\end{tabular}

Nurse education package and Yearly self-learning module

The above table delineates the components of rPOD care bundle that were implemented across the perioperative period.

Domain 1: Establishing Assessment Practices

(A) The baseline vulnerability assessment, including frailty assessment (i.e., Clinical Frailty Scale (CFS)), and cognitive assessment (i.e., Montreal Cognitive Assessment (MoCA)), were implemented. These screening tools were a part of the preoperative assessment package (initially introduce by the Winnipeg Regional Health Authority as a part of a delirium program for all surgical specialties). In addition, a delirium score card (Figure S1) was implemented to assess the risk of postoperative delirium.

(B) During the postoperative period, the Confusion Assessment Method for the ICU (CAM-ICU) screening, [12] and the Critical-Care Pain Observation Tool (CPOT) [13], were introduced in the ICCS unit.

Domain 2: Introducing and Implementing Preventative Strategies

(A) Preoperative: The patient and caregiver delirium education brochure was given during their preoperative visit. The goal was to increase patients' and caregivers' awareness regarding postoperative delirium (i.e., risk factors, signs and symptoms and outcomes). In addition, the brochure provided specific guidelines regarding the patients' and caregivers' roles in aiding early identification and management of delirium.

A 'Getting to know you' form was introduced to gather personal patient information, including family members' names, use of assistive devices (hearing aid, glasses, dentures, mobility aid), profession, interests/hobbies and preferred terms for common activities. Such information could be valuable to the frontline staff to facilitate the cognitive functions during the postoperative recovery period.

(B) Intra operative: A delirium score card was included in the operating room time-out. The patients identified as high risk of delirium, using the delirium score card, received an 
EEG and cerebral capnography-guided anesthesia, to minimize sedation-related neurocognitive dysfunction.

(C) Postoperative: Early mobilization protocol was introduced in the postoperative intensive care unit.

\section{Domain 3: Delirium Care Strategies}

The delirium care strategies included investigating modifiable factors, non-pharmacological and pharmacological interventions (Table 3). In addition, the primary care practitioners were informed of their patients' experiencing delirium and were sent an information pamphlet describing the long-term impact of postoperative delirium which may affect their patient's post-discharge health-related quality of life.

Table 3. Delirium care strategies: the delirium order set.

\begin{tabular}{|c|c|c|}
\hline \multicolumn{3}{|c|}{ A Positive CAM Indicates Delirium, a Medical Emergency and Should Be Translated to Following Action } \\
\hline & Investigations & Interventions \\
\hline- & Vital signs and oxygen saturations & Behavior: T-A-DA T: tolerate as much as possible A: \\
\hline- & Pain assessment (CPOT) & anticipate what agitates them DA: don't agitate them \\
\hline- & Blood sugar & - Sleep-wake cycle promotion: at night use soft voice, lights \\
\hline- & Bladder scan to rule out retention & out, ear plugs, eye masks, promote comfort. \\
\hline- & Last bowel movement to rule out constipation & - Balance rest and activity; mobilize restless patient if safe \\
\hline- & Review fluid input and output to rule out dehydration & - Remember drugs is equal to unconscious, not normal \\
\hline- & Access sensory alterations to evaluate need for glasses, & restorative sleep \\
\hline & hearing aid, sleep deprivation & - Cognition and Communication: Frequent orientation but \\
\hline - & Review lab results, chest $\mathrm{x}$-rays and EKG & do not argue or dispute delusion. Clocks, calendars, \\
\hline - & Consider cultures- blood urine, sputum, wound & hearing aids, glasses, stimulation activities such as cards, \\
\hline- & Consider CT head & crosswords, Sudoku, puzzles \\
\hline- & Review medication especially (anticholinergics) & \\
\hline- & Avoid polypharmacy & \\
\hline- & $\begin{array}{l}\text { Avoid benzodiazepines, consider antipsychotic for } \\
\text { agitated delirium }\end{array}$ & \\
\hline
\end{tabular}

\section{Step 2: Identify Local Barriers to Implementation}

We carefully considered the steps involved in preparing the frontline staff through engaging all relevant stakeholders (ICCS, CSIU, CPAC RN, Physician Assistant) in monthly, multidisciplinary, delirium working group meetings. The goal was to identify barriers to achieve staff buy-ins and implementation. As described in step 4: multiple strategies of the 4 E's model were applied to promote efficient implementation.

The barriers to the rPOD QI project and their management strategies are described in Table 4. An important barrier was the lack of cardiac surgery-specific delirium management guidelines. Through the Plan-Do-Check-Adjust iterative cycle the delirium working group drafted the cardiac science delirium guidelines.

Table 4. Barriers to implementing rPOD intervention at St. Boniface Cardiac Surgery Program.

\begin{tabular}{llll}
\hline \multicolumn{2}{c}{ Barriers } & & \multicolumn{1}{c}{ Strategy to Overcome Barriers } \\
\hline 1 & Lack of leadership & $\bullet$ & $\begin{array}{l}\text { Delirium committee formation consisting of non-physician staff } \\
\text { Establishing cardiac science multidisciplinary delirium working group with } \\
\text { scheduled monthly meetings with a goal of delirium project planning }\end{array}$ \\
\hline 2 & $\begin{array}{l}\text { Lack of delirium-related knowledge } \\
\text { and training among nursing staff }\end{array}$ & $\bullet$ & Multiple education and information sessions to educate and train frontline staff \\
\hline 3 & $\begin{array}{l}\text { Lack of preoperative baseline risk } \\
\text { assessment }\end{array}$ & $\bullet$ & Preoperative delirium risk assessment (CPAC) \\
\hline 4 & Over sedation & $\bullet$ & Screening patients' sedation status using the validated RASS scale [14] \\
\hline 5 & Delirium screening & $\bullet$ & $\begin{array}{l}\text { Screening for delirium by the RN and Physician Assistant using validated } \\
\text { CAM-ICU instrument [15] }\end{array}$ \\
\hline
\end{tabular}


Table 4. Cont.

\begin{tabular}{|c|c|c|}
\hline & Barriers & Strategy to Overcome Barriers \\
\hline 6 & $\begin{array}{l}\text { Perceived pain and discomfort } \\
\text { screening }\end{array}$ & - $\quad$ Assessed pain using validated COPT scale [13] \\
\hline 7 & Early mobilization & $\begin{array}{l}\text { - Obtained dedicated mobilization staff (physiotherapist) and trained them for } \\
\text { screening patients' stability, adjusting mechanical ventilation, securing devices } \\
\text { and untangling of lines and tubes } \\
\text { - } \quad \text { Providing mobilization-enabled ICU equipment }\end{array}$ \\
\hline 8 & $\begin{array}{l}\text { Interventions aimed at preventing } \\
\text { delirium }\end{array}$ & $\begin{array}{l}\text { - A positive CAM indicates delirium a medical emergency and was always } \\
\text { converted to action including investigation and intervention }\end{array}$ \\
\hline 9 & $\begin{array}{l}\text { Lack of patient and caregiver } \\
\text { engagement }\end{array}$ & $\begin{array}{l}\text { - Delirium brochure for patient and caregiver education } \\
\text { - Collecting patient personal information (such as preferred name, use of } \\
\text { hearing/viewing aid) to aid postoperative care provider to understand and } \\
\text { provide for patient preferences and communicate effectively. A "getting to know } \\
\text { you "form was introduced }\end{array}$ \\
\hline 10 & $\begin{array}{l}\text { Lack of communication with the } \\
\text { community physician (family } \\
\text { physician) }\end{array}$ & $\begin{array}{l}\text { - It is essential to provide additional care and support to the patients during their } \\
\text { transition in and out of community } \\
\text { The family physician was informed if the patients were found at risk of delirium } \\
\text { during preoperative assessment as well as if the patient developed delirium } \\
\text { during the postoperative period }\end{array}$ \\
\hline
\end{tabular}

The majority of local barriers were regarding intervention implementation. The rPOD intervention was implemented in sequential and additive stages to limit overwhelming the staff with multiple interventions. Lack of delirium-related education and training among the cardiac surgery frontline health care providers was another important barrier. Multiple information and education sessions were conducted to facilitate staff buy-in. The training was further augmented through the regional health authority's initiative to educate and train all surgical units and patient care staff regarding postoperative delirium and to provide necessary training including assessment tools (CAM ICU, CPOT) and recoding in the electronic patient record.

Step 3: Performance Measure

The process and outcome measures were collected retrospectively (Table 5). Adherence data includes completion rates of baseline risk and POD assessment.

Table 5. Process and Outcome Measures.

\begin{tabular}{|c|c|}
\hline Measure (S) & Mode of Assessment \\
\hline \multicolumn{2}{|r|}{ Process Measures (Intervention adherence) } \\
\hline \multirow{3}{*}{ Intervention adherence } & Rate of completion of baseline risk assessment \\
\hline & Rate of completion of delirium assessment \\
\hline & Outcome Measures \\
\hline \multirow[t]{3}{*}{ Primary outcome } & Rates of delirium screening \\
\hline & $\begin{array}{l}\text { Number of positive CAM screens in clinical database for patients } \\
\text { screened with CAM }\end{array}$ \\
\hline & Number of patients restrained in ICU, Wards \\
\hline \multirow[t]{4}{*}{ Quality indicators } & Hospital LOS, ICU LOS \\
\hline & All-cause in hospital mortality \\
\hline & Major adverse cardiac events \\
\hline & Rate of sternal wound infection \\
\hline
\end{tabular}

The primary outcome measure was the change in the rates of POD screening before, during and after the rPOD care bundle implementation. The quality indicator measures are detailed in Table 5. The performance measures were collected for the ICCS unit, Preoperative assessment clinic and CSIU. In addition, fiscal trends, in terms of departmental 
expenditure, constant care resource utilization for the duration of rPOD implementation and post implementation were also collected.

For the primary analysis, a pre-post design was used to compare outcomes during the baseline pre-intervention period versus when all the rPOD care bundle had been implemented.

Research ethics board approval was provided to collect compliance and quality improvement metrics data for this study

Step 4: Ensuring Complete Intervention Implementation: 4 Es' Model

Engage: Engagement of all stakeholders, from the study leadership to frontline clinical staff, was necessary to ensure buy-in and sustained project adherence. The engagement process included: (1) Conducting educational sessions with a focus on evidence regarding risk factors of delirium, significance of incident delirium and care strategies, as well as presenting results from the previous research delirium study demonstrating delirium rates among cardiac surgery patients at our center, (2) Recruitment of a nurse champion to collaborate on the project, and (3) Monthly review meetings of the delirium working group committee.

Educate: Staff education took place throughout the project. To engage the frontline staff, we administered multiple education and presentation sessions. In these sessions we presented the results of our delirium screening research study and also trained staff to implement the delirium intervention. The nurse champion attended multidisciplinary team meetings and was instrumental in the project design. In preparation for the pilot study, ICCS nurses were briefed on details of the QI project, the daily checklist and delirium screening. During the pilot delirium research study, a member of the ICCS delirium team met frequently with the night shift staff to provide feedback, answer questions and address barriers to future interventions and assessment (baseline risk and delirium screening) completion. In addition, the nursing staff attended educational programs developed by the regional health authority.

Execute: As described in the QI model, there are four general approaches to overcoming implementation barriers. First, the QI team standardized care by orienting all intensive care staff to rPOD care bundles. Second, the QI team used independent reminders, in the form of a checklist and daily verbal reminders from charge nurses and nurse champions to complete the rPOD intervention. Additionally, the QI team introduced a smaller number of interventions at one time using a staged approach. Finally, to learn from problems, throughout the project barriers were reviewed and addressed at monthly delirium working group meetings (Step 2: Identify Local Barriers to implementation).

Evaluate: An "audit and feedback" approach was employed to access group adherence as well as to encourage following of the set standards. The adherence data was presented and discussed with the nurse champion during the monthly delirium working group. Those with high adherence were commended while those with lower adherence were further engaged and educated to facilitate compliance.

\section{Results}

The delirium quality improvement intervention was implemented from 2012 to 2016. Different domains of the intervention may have been implemented simultaneously (Table S1). The adult patients (age $\geq 18$ years) undergoing cardiac surgery were eligible for the intervention and outcome analysis. The corresponding health care providers' compliance data was collected during the cardiac surgery patients' perioperative care transition, including the preoperative, intraoperative and postoperative period. The data about each reporting period has been collected and analyzed.

The median patient age was 67 years (58-74) Table 6 . The preoperative risk, as assessed using MoCA, CFS and PHQ9 (Table 6), were similar between patients across all intervention stages. Additional baseline and ICU data are summarized in the Tables 7 and 8. 
Table 6. Patient Characteristics During Delirium Quality Improvement Period.

\begin{tabular}{|c|c|c|c|c|}
\hline Patient Characteristic & $\begin{array}{l}\text { Pre-rPOD Intervention } \\
\text { (2009-2011) }\end{array}$ & $\begin{array}{c}\text { During-rPOD Intervention } \\
(2012-2015)\end{array}$ & $\begin{array}{l}\text { Post-rPOD Intervention } \\
\text { (2016-2018) }\end{array}$ & $p$-Value \\
\hline Age & $66(58-74)$ & $67(58-74)$ & $68(59-75)$ & $<0.001$ \\
\hline \multirow{2}{*}{\multicolumn{5}{|c|}{ Type of Cardiac Surgery }} \\
\hline & & & & \\
\hline CABG & $60.9 \%$ & $46.9 \%$ & $45.6 \%$ & $<0.001$ \\
\hline Valve & $14.8 \%$ & $20.2 \%$ & $23.0 \%$ & $<0.001$ \\
\hline CABG + Valve & $11.2 \%$ & $11.3 \%$ & $11.1 \%$ & 0.969 \\
\hline Other & $13.1 \%$ & $21.6 \%$ & $20.3 \%$ & $<0.001$ \\
\hline MoCA Score & - & $26(23-28)$ & $26(23-28)$ & 0.479 \\
\hline CFS (Nursing Assessment) & - & $3(2-4)$ & $4(3-4)$ & $<0.001$ \\
\hline $\begin{array}{l}\text { Patient Health Questionnaire } \\
\text { (Version 9) }\end{array}$ & - & $1(0-3)$ & $2(0-6)$ & $<0.001$ \\
\hline
\end{tabular}

Continuous variables expressed as median (quartile 1-3) and compared using Kruskal-Wallis Test. Categorical variables expressed as percentage and compared using Chi-Square Test. Summary statistics calculated on non-missing data. MoCA-Montreal Cognitive Assessment, CFS—Clinical Frailty Scale

Table 7. Outcome Data and Compliance-Process Measures.

\begin{tabular}{cccc}
\hline 7.1. Process Measures & $\begin{array}{c}\text { During-rPOD Implementation } \\
\mathbf{( 2 0 1 2 - 2 0 1 6 )}\end{array}$ & $\begin{array}{c}\text { Post-rPOD Implementation } \\
\text { (2016-2018) }\end{array}$ & $p$-Value \\
MoCA completion rate & 7.1.1 Baseline risk assessment & & $<\%$ \\
CFS completion rate & $30.0 \%$ & $46.6 \%$ & $<0.001$ \\
& $30.7 \%$ & $99.2 \%$ & 0.001 \\
Any CAM Assessment Recorded & $\mathbf{7 . 1 . 2}$ Delirium assessment & $98.5 \%$ & 0.006 \\
Any RASS Assessment Recorded & $97.3 \%$ & $99.2 \%$ & \\
\hline
\end{tabular}

Continuous variables expressed as median (quartile 1-3) and compared using Kruskal-Wallis Test. Categorical variables expressed as percentage and compared using Chi-Square Test. Summary statistics calculated on non-missing data. MoCA-Montreal Cognitive Assessment, CFS—Clinical Frailty Scale.

Table 8. Outcome Data and Compliance-Quality Improvement Measures.

\begin{tabular}{|c|c|c|c|c|}
\hline 7.2. Quality Improvement Measures & $\begin{array}{l}\text { Pre-rPOD Intervention } \\
(2009-2011)\end{array}$ & $\begin{array}{c}\text { During-rPOD Intervention } \\
(201-2016)\end{array}$ & $\begin{array}{c}\text { Post-rPOD Intervention } \\
\text { (2016-2018) }\end{array}$ & $p$-Value \\
\hline \multicolumn{5}{|c|}{ 7.2.1 Primary outcome } \\
\hline $\begin{array}{l}\text { Postoperative delirium } \\
\text { screening rates }\end{array}$ & $9.0 \%$ & $23.3 \%$ & $19.1 \%$ & $<0.001$ \\
\hline \multicolumn{5}{|c|}{ 7.2.2 Quality indicators } \\
\hline $\begin{array}{l}\text { Number of Positive CAM screens } \\
\text { in clinical database for patients } \\
\text { screened with CAM }\end{array}$ & $2(1-4)$ & $2(1-5)$ & $3(1-6)$ & $<0.001$ \\
\hline $\begin{array}{l}\text { Number of patients } \\
\text { restrained-ICU }\end{array}$ & - & $3.0 \%$ & $1.2 \%$ & $<0.001$ \\
\hline $\begin{array}{l}\text { Number of patients } \\
\text { restrained-Ward }\end{array}$ & - & $0.4 \%$ & $0.4 \%$ & 0.955 \\
\hline $\begin{array}{l}\text { Length of ICU stay for patients } \\
\text { screened with delirium (Hours) }\end{array}$ & $79(43-161)$ & $90(42-165)$ & $74(41-147)$ & 0.329 \\
\hline $\begin{array}{l}\text { Length of Hospital Stay (Surgery } \\
\text { to Discharge) for patients } \\
\text { screened with delirium (Days) }\end{array}$ & $12(7-22)$ & $13(8-23)$ & $12(8-23)$ & 0.282 \\
\hline $\begin{array}{c}\text { Major Adverse Cardiac Events } \\
\text { (MI, Stroke, Dialysis, } \\
\text { In-Hospital Mortality) }\end{array}$ & $5.4 \%$ & $8.1 \%$ & $6.3 \%$ & $<0.001$ \\
\hline $\begin{array}{c}\text { Sternal Infection (Superficial } \\
\text { or Deep) }\end{array}$ & $0.2 \%$ & $1.3 \%$ & $1.3 \%$ & $<0.001$ \\
\hline In-Hospital Mortality & $2.5 \%$ & $3.2 \%$ & $2.1 \%$ & 0.012 \\
\hline
\end{tabular}

Continuous variables expressed as median (quartile 1-3) and compared using Kruskal-Wallis Test. Categorical variables expressed as percentage and compared using Chi-Square Test. Summary statistics calculated on non-missing data. 
A total of 3340 patients were evaluated over the study period. We compared the unadjusted assessment completion rates across the intervention period (Table 7). The mean daily preoperative MoCA delivery and completion rates improved from $30 \%$ (30.7\% for CFS) during the r-POD implementation phase to $46.6 \%$ (49.2\% for CFS) in the post implementation phase. However, postoperative delirium assessment rates (considering data of the fully- or partially-completed delirium assessment tool) were similar to rates during and after the post implementation phase.

The quality improvement metrics (outcome-data) before, during and after the implementation of the rPOD intervention are reported in Table 8. The primary outcome measure for the rates of postoperative delirium screening (data only from completed CAM assessments were included) increased during the implementation of the rPOD care bundle and following its implementation. Figure 2 demonstrates the trends of gross expenditure (GL dollars) (Panel A), average patient day constant care or close observation hours and expenditure (Panel B and Panel C), and average in-patient-days (Panel D).
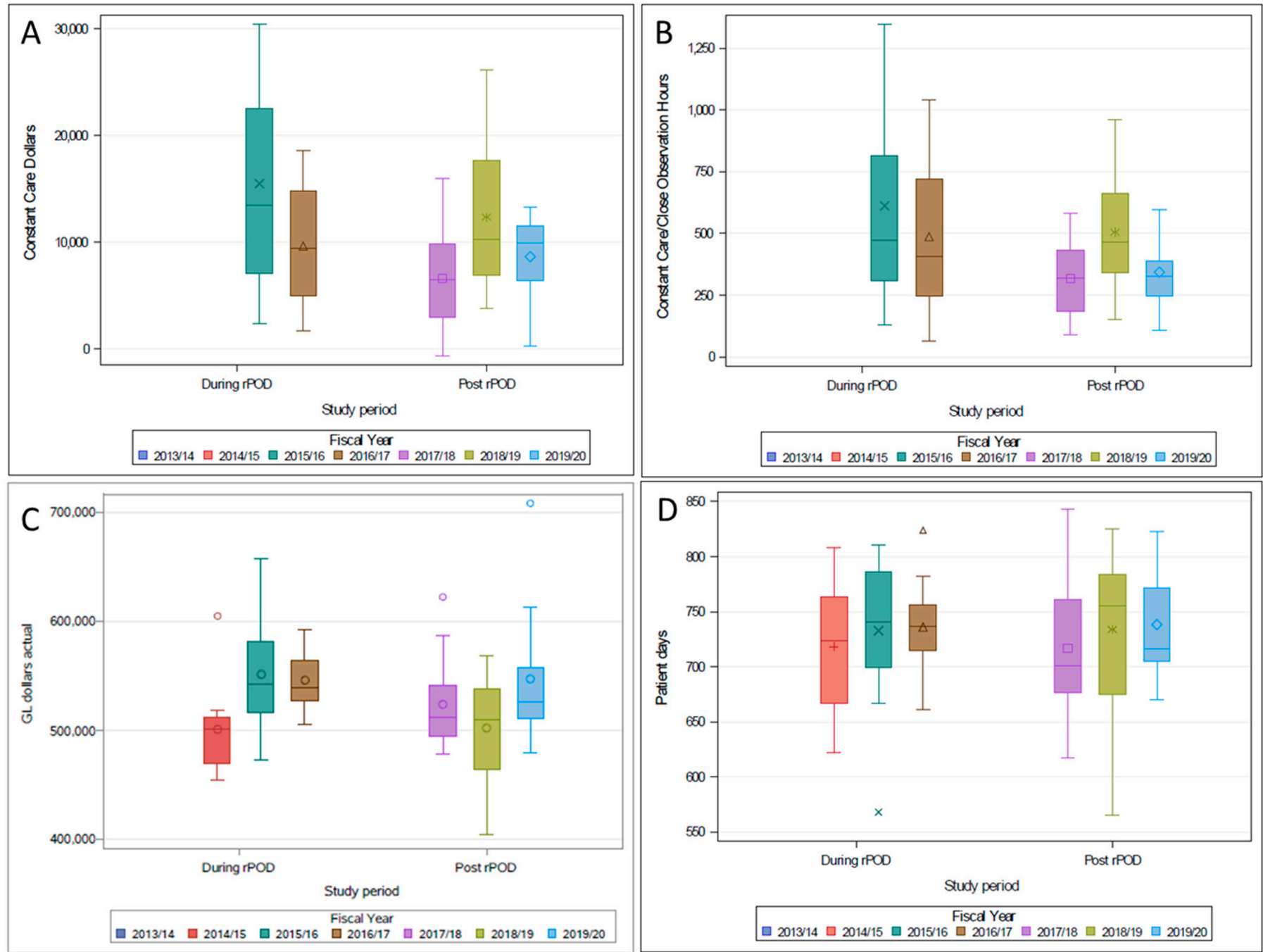

Figure 2. The fiscal trends during (2013-2016) and following (2017-2020) rPOD intervention. Panel (A) —Constant care expenditure by study period, Panel (B) —Constant care observation by study period. Panel (C)—Gross expenditure by study period and Panel (D) - In-patient days by study period. The financial data was collected from the administrative database with the cardiac science program. 


\section{Discussion}

In this study, the QI team used an established QI model to implement the rPOD intervention across the various departments. This model employed a previously successful $4 \mathrm{E}^{\prime} \mathrm{s}$ algorithm (engage, educate, execute, and evaluate). Essential to this effort was the implementation of the rPOD care bundle, which included the preoperative baseline assessment, perioperative preventative strategies and postoperative rapid delirium assessment and care strategies, in successive stages to allow for incremental adoption of the intervention. Using this approach, the QI team demonstrated that multidisciplinary, perioperative and patient-focused interventions for the reduction of postoperative delirium were feasible to be performed on a daily basis, assisting the perioperative care process.

The sustainability of QI projects are challenging. Sustainability is supported by immediate, visible results, which can be difficult in delirium-related projects. Furthermore, identifying and measuring the implementation of new initiatives within health care is difficult without sustainability of these programs over time. Continued staff education delineating the consequences of delirium, frequent feedback to support intervention adoption and identifying patient perspectives could help with the adherence for such an intervention.

A limitation to this project was that more patients underwent CABG during the initial period of this study. Over time more complex surgeries including single and double valve replacement surgery were conducted. This change could have resulted in different levels of cardiac surgical stress and in turn, could have affected the rates of delirium as well as the level of care provided to the patients. Another limitation of this project was, as with other QI projects, uncertainty regarding the generalizability of these results. This project was implemented in a setting led by academic and clinical experts and team members with training and experience in QI projects. However, many of the implementation challenges surmounted in this project, such as continued use of the intervention as part of routine care, are universal to all cardiac surgery units. Furthermore, the established QI model used and the commonsense appeal of these evidence-based rPOD interventions may facilitate its utilization and buy-in for other settings.

\section{Conclusions}

Using an established QI model to implement a multifaceted rPOD intervention to improve delirium care strategies is feasible. The future direction includes the development of strategies to address sustainability and the extension of similar efforts to other cardiac and non-cardiac surgical programs.

Supplementary Materials: The following are available online at https:/ /www.mdpi.com/article/10 .3390/geriatrics6040111/s1, Figure S1: Delirium score card; Table S1: Delirium Quality improvement.

Author Contributions: Conceptualization: R.C.A. and H.G.; Methodology: R.M.S., R.C.A. and S.W.; Data Management: R.M.S. and B.H.; Statistical Analysis: B.H. and R.M.S.; Writing-Original Draft Preparation: R.M.S.; Writing—Review \& Editing: R.M.S., B.H., D.K., S.W., H.G. and R.C.A.; Supervision and Project Administration: D.K. and S.W.; Funding Acquisition: R.C.A. and H.G. All authors have read and agreed to the published version of the manuscript.

Funding: This research received no external funding.

Institutional Review Board Statement: Ethics Approval was received from the University of Manitoba Human Research Ethics Board. HS22352 (H2018:449).

Informed Consent Statement: This study was retrospective in nature and used de-identified data. Therefore, research participant consent was not applicable.

Data Availability Statement: Not applicable.

Acknowledgments: Healthcare providers from the Cardiac Science Program at the St Boniface Hospital.

Conflicts of Interest: The authors declare no conflict of interest. 


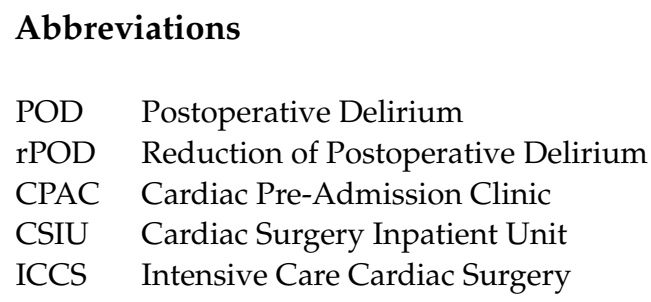

\section{References}

1. Salluh, J.I.; Soares, M.; Teles, J.M.; Ceraso, D.; Raimondi, N.; Nava, V.S.; Blasquez, P.; Ugarte, S.; Ibanez-Guzman, C.; Centeno, J.V.; et al. Delirium epidemiology in critical care (DECCA): An international study. Crit. Care 2010, 14, R210. [CrossRef]

2. Whitlock, E.L.; Vannucci, A.; Avidan, M.S. Postoperative delirium. Minerva Anestesiol. 2011, 77, 448-456. [PubMed]

3. Rudolph, J.L.; Inouye, S.K.; Jones, R.; Yang, F.M.; Fong, T.G.; Levkoff, S.E.; Marcantonio, E.R. Marcantonio ER. Delirium: An Independent Predictor of Functional Decline After Cardiac Surgery. J. Am. Geriatr. Soc. 2010, 58, 643-649. [CrossRef]

4. Brown, C.H. Delirium in the Cardiac Surgical Intensive Care Unit. Curr. Opin. Anaesthesiol. 2014, 27, 117-122. [CrossRef] [PubMed]

5. Marcantonio, E.R.; Goldman, L.; Mangione, C.M.; Ludwig, L.E.; Muraca, B.; Haslauer, C.M.; Donaldson, M.C.; Whittemore, A.D.; Sugarbaker, D.J.; Poss, R.; et al. A clinical prediction rule for delirium after elective noncardiac surgery. JAMA 1994, 271, 134-139. [CrossRef] [PubMed]

6. Rudolph, J.L.; Jones, R.; Rasmussen, L.S.; Silverstein, J.H.; Inouye, S.K.; Marcantonio, E.R. Independent vascular and cognitive risk factors for postoperative delirium. Am. J. Med. 2007, 120, 807-813. [CrossRef] [PubMed]

7. Marcantonio, E.R.; Flacker, J.M.; Michaels, M.; Resnick, N.M. Delirium is independently associated with poor functional recovery after hip fracture. J. Am. Geriatr. Soc. 2000, 48, 618-624. [CrossRef] [PubMed]

8. Franco, K.; Litaker, D.; Locala, J.; Bronson, D. The cost of delirium in the surgical patient. Psychosomatics 2001, 42, 68-73. [CrossRef] [PubMed]

9. Arora, R.C.; Djaiani, G.; Rudolph, J.L. Detection, Prevention, and Management of Delirium in the Critically Ill Cardiac Patient and Patients Who Undergo Cardiac Procedures. Can. J. Cardiol. 2017, 33, 80-87. [CrossRef] [PubMed]

10. Boustani, M.; Baker, M.S.; Campbell, N.; Munger, S.; Hui, S.L.; Castelluccio, P.; Farber, M.; Guzman, O.; Ademuyiwa, A.; Miller, D.; et al. Impact and recognition of cognitive impairment among hospitalized elders. J. Hosp. Med. Off. Publ. Soc. Hosp. Med. 2010, 5, 69-75. [CrossRef] [PubMed]

11. Pronovost, P.J.; Berenholtz, S.M.; Needham, D.M. Translating Evidence into Practice: A Model for Large Scale Knowledge Translation. BMJ 2012, 337, 963-965. [CrossRef] [PubMed]

12. Ely, E.W.; Margolin, R.; Francis, J.; May, L.; Truman, B.; Dittus, R.; Speroff, T.; Gautam, S.; Bernard, G.R.; Inouye, S.K. Evaluation of delirium in critically ill patients: Validation of the Confusion Assessment Method for the Intensive Care Unit (CAM-ICU). Crit. Care Med. 2001, 29, 1370-1379. [CrossRef] [PubMed]

13. Gélinas, C.; Fillion, L.; Puntillo, K.A.; Viens, C.; Fortier, M. Validation of the critical-care pain observation tool in adult patients. Am. J. Crit. Care 2006, 15, 420-427. [CrossRef] [PubMed]

14. Ely, E.W.; Truman, B.; Shintani, A.; Thomason, J.W.W.; Wheeler, A.P.; Gordon, S.; Francis, J.; Speroff, T.; Gautam, S.; Margolin, R.; et al. Monitoring sedation status over time in ICU patients: Reliability and validity of the Richmond Agitation-Sedation Scale (RASS). JAMA 2003, 289, 2983-2991. [CrossRef] [PubMed]

15. Ely, E.W.; Inouye, S.K.; Bernard, G.R.; Gordon, S.; Francis, J.; May, L.; Truman, B.; Speroff, T.; Gautam, S.; Margolin, R.; et al. Delirium in mechanically ventilated patients: Validity and reliability of the confusion assessment method for the intensive care unit (CAM-ICU). JAMA 2001, 286, 2703-2710. [CrossRef] [PubMed] 